J. Neurol. Neurosurg. Psychiat., 1955, 18, 191.

\title{
ON THE MUSCULAR RIGIDITY AND HYPERREFLEXIA DUE TO HYPOTHERMIA IN MAN WITH OBSERVATIONS ON THE ACCOMMODATION OF PERIPHERAL NERVE
}

\author{
BY \\ JOHN A. SIMPSON \\ From the Gardiner Institute of Medicine, University of Glasgow
}

Before the development of controlled hypothermia as a therapeutic measure in man little was known of the effects of prolonged lowering of the body temperature in the human subject. The pioneering work of Smith and Fay (1940) and of Talbott $(1941,1944)$ in the use of refrigeration for the treatment of malignant disease, schizophrenia, and intractable pain has found little support and the technique is now most widely used as a means of lowering metabolism during surgical operations (Lewis and Taufic, 1953). The earlier work enabled studies to be made on the conscious subject in conditions suitable for observation. The effect of progressive hypothermia on the human nervous system was described by Davis (1940), Fay and Smith (1941), and Dill and Forbes (1941). A striking feature of these reports was the hyperreflexia and muscular rigidity shown by the majority of patients at a particular range of temperatures. These authors were unable to give a satisfactory explanation of this phenomenon. This paper reports observations on a case of spontaneous hypothermia which suggest a possible mechanism.

The clinical picture of progressive hypothermia is described by Fay and Smith (1941) in a report based on a study of 42 patients who were treated by controlled cooling for various malignant diseases. In three patients, in whom spinal anaesthesia was used during the early stage of refrigeration, cerebration was progressively delayed with the reduction of body temperature. Mental faculties were fairly well preserved until the body temperature approached $93^{\circ} \mathrm{F}$. but there was retrograde amnesia for the period during which the body temperature remained below $92^{\circ} \mathrm{F}$. Dysarthria began at approximately $93^{\circ} \mathrm{F}$. and response to the spoken word became practically nil below $80^{\circ} \mathrm{F}$. Pain present before refrigeration was completely relieved in all but $4.7 \%$ of the 42 cases but appreciation of pain, heat, and cold was not lost during or after refrigeration as long as consciousness was retained. The pupils remained equal, regular, and normal in size through- out the hypothermic period, but response to light stimuli became progressively more sluggish as the body temperature was lowered. The light reflex was abolished at $78^{\circ} \mathrm{F}$. The psychical and pupillary changes resemble those of pharmacological anaesthesia and, indeed, it would not be surprising that the cerebrum should cease to function when its metabolism is lowered by cold (Fazekas and Himwich, 1939) in a manner closely resembling the effects of chemical inhibitors of metabolism. An unusual feature, however, compared with chemical anaesthesia is the retention of muscle tone and the stretch reflexes. The clinical picture vividly described by Fay and Smith (1941) emphasizes this unique feature :-

"As the body temperature was lowered, the muscles of the extremities assumed a waxy stiffness and when percussed contracted slowly, with subsequent slow relaxation and return to their normal contour. Spontaneous myokymia was observed in patients with temperatures as low as $84^{\circ} \mathrm{F}$.; if the phenomenon was not present at this temperature level, it occurred when passive mction of a joint was made.

The patients assumed a characteristic posture denoting cold, with arms held close to the sides and hands against the upper portion of the chest and beneath the chin.

The upper and lower extremities assumed a flexed position, and considerable effort was required to extend them. In a strong patient it was frequently difficult to extend the arm sufficiently to take blood pressure readings. The wrists were flexed; the hands did not form the fist position but took a 'clawlike' attitude. The metacarpo-phalangeal joints remained extended, though the interphalangeal joints remained flexed. The patients attempted to curl up into a ball during the shivering phase. When the rectal temperature was reduced below approximately $8 \varepsilon^{\circ} \mathrm{F}$. shivering ceased and the patients were comparatively comfortable though not relaxed, for the increased muscular tone remained. . . . All volitional movements became progressively slower and incoordination gradually more pronounced as the body temperature continued to fall. The slowed hypertonic movements of the Parkinsonian state are simulated, though the incoordination noted here was more pronounced. No athetotic, dystonic, or choreic movements were observed. 
... The deep tendon reflexes, abdominal, and gag reflexes were abolished at a temperature level approximately $78^{\circ} \mathrm{F}$."

No extensor plantar reflexes were seen in subjects who did not show this response before cooling. There were no permanent neurological sequelae on rewarming. It is not clear from their account whether the characteristic posture and muscle stiffness persisted after the deep reflexes had disappeared but Dill and Forbes (1941), describing similar cases, mention that rigidity and hyperreflexia may be present when the body temperature is only slightly reduced and absent at lower temperatures. Davis (1940) thought that the " pseudospasticity" was probably local though his cases also showed hyperreflexia. Gagge and Herrington (1947) state that resuscitation is unsuccessful if refrigeration is taken to the stage at which rigidity ceases.

Severe muscular rigidity was observed in a case of accidental hypothermia reported by Laufman (1951). He seems to have considered that the muscles were actually "frozen", though the point is not discussed. Increased reflex activity and resistance to passive movement were prominent in the subject of the present report.

\section{Case History}

A 77-year-old man was found by the rent collector lying apparently dead in the house in which he lived alone. He had not been seen by his neighbours for four days. The police were called and it was then established that, although the body was extremely cold, the man was breathing. He was admitted to the Western Infirmary, Glasgow, on February 17, 1953.

The general state of nutrition was fair but the tongue was dry and the eyeballs soft. He had a two or three days' growth of beard; the body hair was normal. There was a bruise on the right shoulder and a purpuric rash on the front of the thighs. The face and limbs were cyanosed. A clinical thermometer in the mouth did not record. A lotion thermometer inserted about 2 in. into the rectum recorded $22 \cdot 5^{\circ} \mathrm{C}$. $\left(72 \cdot 5^{\circ} \mathrm{F}\right.$.). Respiration was infrequent $(7 / \mathrm{min}$.) and shallow. No pulses could be felt in the limb or carotid arteries; the heart sounds were inaudible. The peripheral veins, however, were full and refilled rapidly when emptied.

On admission he was deeply comatose and did not respond to painful stimuli but during further examination he became restless and made powerful movements of all four limbs. Resistance to passive movement of the limbs was considered normal or slightly increased and was maintained throughout the range of movement. There was no nuchal rigidity and Kernig's sign was absent. All tendon reflexes were present and symmetrical. The abdominal reflexes were absent; the plantar responses were flexor. The pupils were contracted and did not react to light. The eyeballs were fixed in the midposition. The corneal reflexes were absent. The fundi could not be seen because of corneal abrasions.
No primary cause for the profound hypothermia was evident. Urine, obtained by catheterization, contained no abnormal constituents.

Progress.-The body was warmed slowly by a radiant heat cage. Frequent measurements of temperature were made with a rectal thermometer and a thermocouple skin thermometer on the forehead (the only accessible area clear of the heat cage). After two hours of warming, the rectal temperature had risen to $23^{\circ} \mathrm{C}$. and the radial pulse became palpable. The respiratory rate rose to 12 per minute. Restlessness increased and movements of the limbs became more powerful and hard to restrain passive extension of the arms was particularly difficult, causing difficulty in using a sphygmomanometer. For a period between four and eight hours after admission a systolic pressure of 50 to $60 \mathrm{~mm}$. $\mathrm{Hg}$ was recorded. An E.C.G. at three and a half hours (rectal temperature $25.5^{\circ} \mathrm{C}$.) showed sinus rhythm at 32 per minute with a prolonged Q-T interval and shallow inverted $\mathrm{T}$ waves in the three standard leads.

Haematological examination (Dr. H. Conway) showed severe thrombocytopenia, absolute lymphopenia, total absence of eosinophils, and a "shift to the left" of the neutrophil series.

Biochemical findings were : plasma urea, $143 \mathrm{mg} . \%$; plasma non-protein nitrogen, $108 \mathrm{mg} . \%$; plasmat proteins, $6.36 \mathrm{~g} . \%$ (albumin $4 \cdot 33$, globulin $1 \cdot 74$, fibrino-0 gen 0.29); plasma chlorides (as $\mathrm{NaCl}$ ), $570 \mathrm{mg} \% \%$ 霓 serum calcium, $9.5 \mathrm{mg} \%$; serum inorganic PO4, $6.8 \mathrm{mg} . \%$; blood sugar, $90 \mathrm{mg} . \%$; plasma cholesterol $152 \mathrm{mg} . \%$. The cephalin flocculation test was negative as also that for colloidal gold.

The rectal temperature rose slowly (about $1^{\circ} \mathrm{C}$. pe? hour) during the first 10 hours after admission and the patient's general condition seemed better. Though hedid not recover consciousness he continued to resist passive movement and began to withdraw from painful stimuli. When not disturbed he lay on his back with his elbows close to his sides, arms flexed, fingers clenched, and knees drawn up. At intervals he made strong extension movements of a single limb. The tendon jerks were then very brisk. After 10 hours the pulse again became difficult to feel and the rectal temperature stopped rising. Roving dissociated movements of the eyeballs were noted. An intravenous drip was started and over the next seven hours two pints of plasma and one pint of $5 \%$ glucose were given. The radial pulse returned but the blood pressure was still not recordable. An E.C.G. at 17 hours (rectal temperature $31^{\circ}$ C.) still showed sinus bradycardia with occasional auricular extrasystoles but the Q-T interval was shorter and $T_{1}$ and $T_{2}$ were now upright. From 18 to 22 hours his condition remained stationary and thereafter slowly deteriorated. He died 23 hours after admission.

Nerve Accommodation.-By the method of Solandt (1936) and with Andrew's (1952) stimulator three measurements of the time-constant $(\lambda)$ of accommodation (Hill, 1936) of the right ulnar nerve were made when the rectal temperature was 23 to $26^{\circ} \mathrm{C}$. The values of $\lambda$ calculated from the curves shown in Fig. 1 were in the range 128 to $235 \mathrm{~m} . \mathrm{sec}$. The range in 32 normal adults 
was 30 to $100 \mathrm{~m} . \mathrm{sec}$., which agrees closely with the findings of Kugelberg (1944). The values obtained in the hypothermic patient are comparable with those found in patients with latent tetany (Fig. 1).

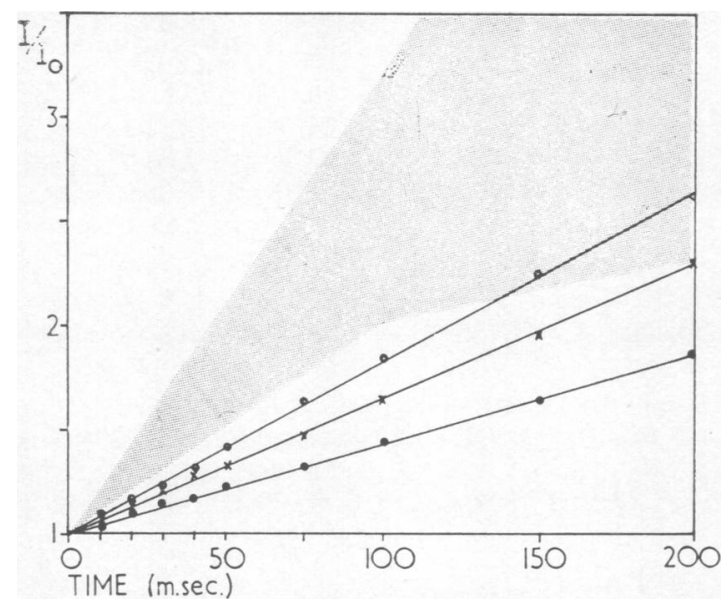

FIG. 1.-Three curves of threshold of the right ulnar nerve at the elbow to progressively rising (exponential) currents. Ordinate in multiples of rheobase $(R=1)$, abscissa in m.sec. (time-constant of current rise). The index of response was a palpable twitch of the flexor carpi ulnaris at the wrist. The time-constant of accommodation $(\lambda)$ is the reciprocal of the initial slope of the curve. (The shaded area shows the range of the accommodation curve of the ulnar nerve at the elbow in normal adults.)

Post-Mortem Examination.-Necropsy performed by Dr. H. E. Hutchison 18 hours after death showed aleukaemic lymphatic leukaemia with terminal hypostatic pneumonia. There were two small areas of cerebral softening, one in the right insula $(1 \mathrm{~cm}$. diameter) and an even smaller one in the right upper medulla. The brain, spinal cord, and peripheral nerves showed no other macro- or microscopic lesion. The glycogen content of the liver was severely reduced and none was present in a sample of the thigh muscle. The pituitary body was normal and the thyroid $(7 \mathrm{~g}$.$) and adrenals (total 8 \mathrm{~g}$.) though small were microscopically normal. In particular, the lipoid content of the adrenal cortex was not reduced.

Cause of Hypothermia and Death.-Because of the absence of hypothalamic, bilateral medullary, cervical cord, or endocrine disease sufficient to cause hypothermia from disturbance of thermoregulation and since there was evidence suggesting a fairly heavy fall on the right side, it is presumed that this old man fell, probably with sufficient severity to cause concussion. The small cerebral infarcts seemed too recent and too small to have caused his collapse. Bender (1928) and Rewerts (1949) found congestion and miliary haemorrhages in all parts of the brain in men who had died after prolonged exposure to severe cold. There was also vacuolization of nerve cells in Bender's (1928) case. In the present case the cause of hypothermia is uncertain. The aleukaemic leukaemia must surely have been coincidental. It seems likely that, after a fall, the patient lay, probably uncon- scious, for three or four days. He was indoors and well clad and the weather was average for the season. The maximum and minimum temperatures in Glasgow during the four days were $48^{\circ} \mathrm{F}$. $\left(9^{\circ} \mathrm{C}\right.$. $)$ and $30^{\circ} \mathrm{F}$. $\left(-1^{\circ} \mathrm{C}\right.$.) respectively. These temperatures were higher than those to which other reported patients with accidental hypothermia were exposed but, bearing in mind the age of the patient and the period for which he lay immobile, the climatic conditions were sufficient to cause hypothermia when it is considered that an unclothed conscious person remaining as motionless as possible while tensing all the limb muscles is unable to prevent a slow fall in body temperature at an environmental temperature as high as $27^{\circ} \mathrm{C}$. and finds this very exhausting work (Hardy, Milhorat, and DuBois, 1938). It has been calculated (Hardy and Soderstrom, 1938) that an ordinary sized man, exposed nude at $23^{\circ} \mathrm{C}$., would have to produce at least 2,300 to 2,500 calories per day simply to maintain body heat and that below $28^{\circ} \mathrm{C}$. the motionless human body cools as a physical body. The exhaustion of liver and muscle glycogen, with evidence of adequate thyroid, pituitary and adrenal function, suggests that the normal heat conservation mechanisms had been fully utilized and exhausted.

\section{Discussion}

The lowest rectal temperature compatible with life is unknown. In the human subjects of German experiments, sudden cooling of the body in water at 4 to $6^{\circ} \mathrm{C}$. invariably caused death when the rectal temperature fell below $28^{\circ} \mathrm{C}$. (Gagge and Herrington, 1947), but survival with a lower rectal temperature resulting from gradual exposure to cold air has been recorded (Reincke, 1875 ; Laufman, 1951). Laufman's (1951) case is the only one recorded in which the rectal temperature was lower than in the present patient.

The circumstances of accidental hypothermia and the overruling requirements of therapy restrict the amount of physiological observation possible but there is a unique advantage in that observations can be made on patients with a body temperature lower than would be justifiable in therapeutic or experimental hypothermia. The patient reported here showed profound suppression of all vital activity and, indeed, was barely living. The postmortem findings suggest that his body's metabolism was insufficient to counter its loss of heat to the environment. When the body was heated slowly the pulse rate gradually increased, respiration deepened, and the patient began to make reflex responses to cutaneous stimuli. The eyeballs, at first fixed, began to rove independently. The tendon reflexes were never completely absent and were brisk even when the rectal temperature was $22.5^{\circ} \mathrm{C}$. The resistance of the limbs to passive movement was considered normal. As the temperature increased, the response to sensory stimuli became more generalized and 
even violent. At this stage (rectal temperature $26^{\circ} \mathrm{C}$.) the arms were held close to the side with the forearms flexed and the hands clenched; the thighs and legs were flexed. The position recalls that described by Fay and Smith (1941). The tendon jerks were then very brisk but the plantar reflexes remained plantiflexor throughout. The resistance to passive movement was then greatly increased; it became extremely difficult to extend the arm for recording the blood pressure. When the observations were made it was considered that the increased resistance to passive movement was due to uninhibited withdrawal from stimuli and that the posture was similar to that adopted by other unconscious subjects, but the subsequent review of the literature on hypothermia suggests that this is not an adequate explanation since one has to postulate a state of increased reflex activity accompanying a profound cerebral inhibition but without obvious pyramidal or extrapyramidal damage in life or on post-mortem examination. It seems probable that the remarkable retention of muscle tone and reflex activity was of the same order as that described by Fay and Smith (1941). These authors recorded the phenomenon without explaining it. Dill and Forbes (1941) were equally at a loss while recognizing that the muscles could hardly be in a state of voluntary contraction, nor could the condition be described as a true "cold rigor" of muscle since it was abolished by further lowering of the temperature. Contracture, abolished by further cooling but reappearing during rewarming to a certain temperature range and leaving no sequelae, could not be due to the necrotic lesions described in frozen muscle by Nageotte (1937) and by Smith, Ritchie, and Dawson (1915), and in immersion foot by Blackwood (1944), nor would a myogenic contracture be accompanied by hyperreflexia. Kottke, Phalen, and Visscher (1944) considered the possibility that the muscular rigidity was due to " non-apparent shivering", which would give the phenomenon some survival value. Certainly dogs subjected to cold show muscle rigidity at a temperature below that at which shivering disappears (Hegnauer and Penrod, 1950). Similar phenomena were noted during cold narcosis in cats by Simpson and Herring (1905) and Hamilton (1937). It is possible that cold affects both the excitation and the contraction mechanisms of skeletal muscle by slowing metabolic processes (Walker, 1949).

In laboratory animals cold has been shown to enhance spinal reflex activity (Toennies, 1938 ; Grundfest, 1941), to cause synaptic facilitation (Granit and Skoglund, 1945), and to induce iterative response of peripheral nerve (Katz, 1936; Hoff and Grant, 1944). The latter phenomena are attributed to reduced nerve accommodation (Schoepfle and Erlanger, 1941 ; Erlanger, Blair, and Schoepfle, 1941 ; Skoglund and Uvnäs, 1943). The time-constant of accommodation of frog nerve was shown to be increased by cooling by Solandt (1936) and by Schriever and Cebulla (1938). No complementary studies have been reported in the human subject. In the patient reported above the timeconstant of accommodation of the right ulnar nerve was 128 to $235 \mathrm{~m} . \mathrm{sec}$. which is comparable with that found in latent tetany. No hypocalcaemia was present in this or in other recorded cases (Bernhard, 1940 ; Talbott, 1941). These workers found no evidence of alkalosis ; indeed hypothermic patients tend to develop acidosis (Dill and Forbes, 1941). The other cations were not determined in this case but the plasma sodium and potassium levels have been normal in the cases in the literature except in the presence of renal azotaemia (Laufman, 1951).

Diminished accommodation of peripheral nerve (increased $\lambda$ ) is usually accompanied by lowering of the rheobase (Kugelberg, 1944) and results in repetitive firing of motor-units in response to as single stimulus to the axone or arising spontaneouslyd as in manifest tetany. It seems highly probable that this is a major factor in the hyperreflexia of hypo -thermia and the hypertonic state may be analogouse to spontaneous tetany. If a peripheral nerve iso further cooled, increased refractory period (Adrian? 1914) and conduction block (Gasser, 1931) become dominant until eventually " cold block" occurs? The biphasic effect suggested here is not peculiar to cold. Almost identical results follow various grades of ischaemia in a peripheral nerve. It seems probable that cold and anoxia each slow and eventually prevent enzymatic processes responsible for the oxidative metabolism of nerve which maintains membrane potential and restores the membrane after depolarization (Lorente de Nó, 1947). Unfortunately I was not familiar with the physiological literature when the observations were made and the accommodation curves were not computed immediately so that the resemblance of the muscular rigidity to that of tetany was not appreciated.

It is possible that cold may have a similar action on the accommodation of muscle fibre, and indeed this is the probable explanation for the well-known potentiation of myotonia by cold, but such an action could not explain the muscular rigidity observed unless accommodation was so reduced as to cause prolonged spontaneous firing of muscle fibres. The technique of investigation used is a measure of nerve excitability and does not give information about the state of the muscle. I have investigated 
the accommodation of nerve and muscle in myotonia congenita and dystrophica. In these conditions the muscle accommodation is lowered but the accommodation of peripheral nerve is normal. The so-called " myotonia" of hypothyroidism is due to slow relaxation of the contractile substance and not to repetitive firing of muscle fibres. This type of hypometabolic activity may well be present in hypothermia (Walker, 1949) but obviously cannot explain the maintained rigidity.

It is not suggested that shivering has a similar mechanism since it has been shown to be dependent on central pathways (Uprus, Gaylor, and Carmichael, 1935), though a change in peripheral nerve accommodation might serve as an economical amplifying factor. Burton and Bronk (1937) have noted a change in the quality of spontaneous muscle activity (of cats) as cooling increased.

Later observers may be able to answer two questions : (1) Is cold rigidity present in the lower limbs of a paraplegic patient, and (2), Can the Trousseau phenomenon be demonstrated in the presence of cold hyperreflexia before rigidity develops ? If the suggestions made in this paper are correct both answers should be positive. The current use of cold anaesthesia may enable the proposition to be tested.

I am grateful to Drs. Conway, Marr, Meikle, and Richards for assisting in keeping the patient under continuous observation, Mr. S. L. Rae for biochemistry, Dr. H. E. Hutchison for the necropsy report, and Mr. A. Andrew, of the Department of Physiology, for the use of his stimulator. Sir John McNee kindly permitted the investigations and Dr. E. A. Carmichael, C.B.E., read the manuscript.

\section{REFERENCES}

Adrian, E. D. (1914). J. Physiol., Lond., 48, 453.

Andrew, A. M. (1952). Electron. Enging, 24, 334

Bender, L. (1928). Arch. Neurol. Psychiat., Chicago. 20, 319.

Bernhard, A. (1940). Bull. N.Y. Acad. Med., 16, 322.

Blackwood, W. (1944). Brit. J. Surg., 31, 329.

Burton, A. C., and Bronk, D. W. (1937). Amer. J. Physiol., 119, 284.

Davis, T. K. (1940). Bull. N.Y. Acad. Med., 16, 324.

Dill, D. B., and Forbes, W. H. (1941). Amer. J. Physiol., 132, 685.

Erlanger, J., Blair, E. A., and Schoepfle, G. M. (1941). Ibid., 134, 705.

Fay, T., and Smith, G. W. (1941). Arch. Neurol. Psychiat., Chicago, $45,215$.

Fazekas, J. F., and Himwich, H. E. (1939). Proc. Soc. exp. Biol., N.Y., 42, 537.

Gagge, A. P., and Herrington, L. P. (1947). Ann. Rev. Physiol., 9, 409.

Gasser, H. S. (1931). Amer. J. Physiol., 97, 254.

Granit, R., and Skoglund, C. R. (1945). J. Neurophysiol., 8, 211.

Grundfest, H. (1941). Amer. J. Physiol., 133, 307.

Hamilton, J. B. (1937). Yale J. Biol. Med., 9, 327.

Hardy, J. D., Milhorat, A. T., and DuBois, E. F. (1938). J. Nutr., $16,477$.

- and Soderstrom, G. F. (1938). Ibid., 16, 493.

Hegnauer, A. H., and Penrod, K. E. (1950). U.S. Armed Forces Tech. Rept. No. 5912, pp. 1-108.

Hill, A. V. (1936). Proc. roy. Soc. B., 119, 305.

Hoff, H. E., and Grant, R. S. (1944). J. Neurophysiol., 7, 305.

Katz, B. (1936). J. Physiol., Lond., 88, 239.

Kottke, F. J., Phalen, J. S., and Visscher, M. B. (1944). Fed. Proc., $3,26$.

Kugelberg, E. (1944) Acta physiol. scand., 8, Suppl. XXIV.

Laufman, H. (1951). J. Amer. med. Ass., 147, 1201.

Lewis, F. J., and Taufic, M. (1953). Surgery, 33, 52.

Lorente de Nó, R. (1947). A Study of Nerve Physiology, Pt. 2, p. 315. Studies from the Rockefeller Institute for Medical Research, vol. 132 .

Nageotte, J. (1937). Z. Zellforsch., 26, 603.

Reincke, J. J. (1875). Dtsch. Arch. klin. Med., 16, 12.

Rewerts, G. (1949). Dtsch. med. Wschr., 74, 1365.

Schoepfle, G. M., and Erlanger, J. (1941). Amer. J. Physiol., 134, 694. Schriever, H., and Cebulla, R. (1938). Pflügers Arch. ges Physiol., 241, 1 .

Simpson, S., and Herring, P. T. (1905). J. Physiol., Lond., 32, 305.

Skoglund, C. R., and Uvnäs, B. (1943). Acta physiol. scand., 6, 149. Smith, J. L., Ritchie, J., and Dawson, J. (1915). J. Path. Bact., 20,

Smith, L. W., and Fay, T. (1940). Amer. J. clin. Path., 10, 1.

Solandt, D. Y. (1936). Proc. roy. Soc. B., 119, 355.

Talbott, J. H. (1941). New Engl. J. Med., 224, 281. Book Publishers, Chicago,

Toennies, J. F. (1938). J. Neurophysiol., 1, 378.

Uprus, V., Gaylor, G. B., and Carmichael, E. A. (1935). Brain, 58, 220.

Walker, S. M. (1949). Amer. J. Physiol., 157, 429. 